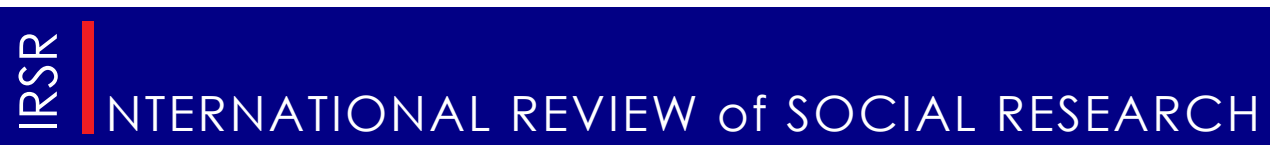

Volume 3, Issue 2, June 2013, 69-87

International Review of Social Research

\title{
Prenatal Googling: Online Information Seeking by Israeli Women During Pregnancy
}

\author{
Eimi LEV \\ Department of Communication \\ Tel-Aviv University
}

\begin{abstract}
In recent years, the internet has become a popular medium for pregnant women seeking pregnancy-related information (Gao et al., 2012; Lagan, Sinclair \& Kernohan, 2010; Romano, 2007; Song, West, Lundy \& Smith-Dahmen, 2012). This study which utilized a qualitative approach explores Israeli women's online information seeking during pregnancy. Israel is an especially interesting and important case study for exploring pregnancy-related internet use, because Israel has the highest rate of prenatal testing in the world (Lavi, 2010). The findings of this study indicated that the most prominent type of information sought by Israeli pregnant women online was focused on prenatal tests. The internet as a source of pregnancyrelated information seems to function not just as a means to fulfill personal informational needs, but also to represent a broader social phenomenon of a highly medicalized pregnancy that seem to intensify uncertainty and therefore, to increase the need to rely on the internet during pregnancy.
\end{abstract}

Keywords: internet, pregnancy, health information seeking, prenatal tests, Israel.

\section{Introduction}

Pregnancy in western cultures is an observable process coming under scientific monitoring and scrutiny (Young, 1995). Although pregnancy is generally seen as a natural phenomenon and is not considered to be an illness or disease, it is a condition that has become highly scrutinized by the medical system and, therefore, includes physical exams, medical monitoring, and prenatal tests (Crum, 2000). Consequently, many pregnant women in industrialized countries utilize the internet as a primary resource of information about pregnancy and as a mean to help them

e-mail:elev@post.tau.ac.il, Eimi Lev is a Lecturer in the Department of Communication at Tel-Aviv University. 
deal with uncertainties related to this process, and navigate pregnancyrelated decisions (Lagan, Sinclair \& Kernohan, 2010; Romano, 2007; Song, West, Lundy \& Smith-Dahmen, 2012). I believe that understanding women's online information seeking during pregnancy can shed more light on this phenomenon and have practical implications for better addressing pregnant women's needs. Therefore, this study aims to explore online information seeking and internet use within the context of pregnancy utilizing the Uses and Gratifications Perspective (Katz, Blumer, \& Gurrevitch, 1974) as a theoretical framework.

This study is focused on internet use in Israel during pregnancy. As a native Israeli, I was able to conduct this research and interview participants in my native tongue. Also, as a female who was born, raised, and resides in Israel, I felt that I possess a shared cultural understanding with my participants which allowed me to communicate with them in a manner that promoted open conversation and, thus, could elicit rich information.

Israel is a particularly appropriate and intriguing context to study internet use by pregnant women, because it is a leading nation in the number and types of prenatal tests. As such, Israel has the highest rate of prenatal testing in the world (Lavi, 2010). Prenatal testing during pregnancy can amplify pregnant women's informational needs to understand the meaning and implications of these procedures. Since prenatal testing is widely accepted in other western countries (de Jong et al., 2010), the manner in which Israeli pregnant women use the internet to seek relevant information could provide insight into online information seeking practices of pregnant women in other countries.

Another compelling reason to conduct the study in Israel is because it has relatively high internet usage rates. Mano, Mesch and Tsamir (2011) conducted a survey of a representative sample of the Israeli population in 2010 , and found that $71.8 \%$ of 18 and more years old surf the Internet. Data from this survey also suggests that the Internet population in Israel is characterized by a high percentage of young people (18-45 years old), and that $62 \%$ of respondents engage in practices of online health information seeking. In the following sections, I will review literature relevant to this study. Also, I will provide an explanation of the theoretical framework and the methodological approach used in this study.

\section{Literature Review}

\section{Online Health Information Seeking}

Research shows that growing numbers of internet users are utilizing the internet for purposes of health information seeking (Fox, 2011; Lorence, Park \& Fox, 2006). In the United States, $80 \%$ of internet users turn to the internet to seek healthrelated information (Fox, 2011). Stern, Cotten \& Drentea (2012) assert that in the United States 'more people will visit a health-related website than an actual health service professional on any given day' (p.1325).

Health information seeking is a common practice among individuals because information is necessary 
to make sense of different health situations, their implications, and available options. As Talosig-Garcia and Davis (2005) stated, 'information plays a key role in helping patients understand their disease process, and enabling them to make informed medical decisions' (p. 53). Tang and Lee (2006), who explored motivations for internet use for health information in Singapore utilizing focus groups, found three types of personal needs. These three types of needs were curiosity, health management, and a sense of control. Curiosity was explained as the need to know about a certain issue. Health management was explained as the knowledge necessary to maintain a healthy lifestyle, cope with an illness, self diagnose an existing medical condition, or better understand a medical diagnosis or a treatment. The third type of need, a sense of control, was explained as the need for knowing in order to reduce uncertainty which can lead to distress. All these types of personal needs indicated that information seeking was perceived by participants as a way to deal with uncertainty regarding a health condition (pp. 116-117). Babrow (2001) asserted that 'uncertainty exists when details of situations are ambiguous, complex, unpredictable, or probabilistic when information is unavailable or inconsistent; and when people feel insecure in their own state of knowledge or the state of knowledge in general' (p. 477). Thus, the basic idea behind the notion of uncertainty management is that individuals have a drive to reduce uncertainty in order to make the world more predictable

\section{Women as Health Information Seekers}

The notion of women as health information seekers is supported by research findings suggesting that women tend to go online for health information more than men do (Fox, 2011; Lemire, Pare, Sicotte \& Harvey, 2008). Lagan, Sinclair \& Kernohan (2006) reported that there is a growing body of literature on women's increasing use of the internet for health information seeking. One of the explanations for this tendency, according to the authors, is related to the traditional role of women as mothers and care-givers for their family. Within this role, women usually regard themselves as responsible for the well being of their family members and, therefore, become more active in searching for information about personal health.

One of the most prevalent and natural life situations that may increase the need for more healthrelated information among women is pregnancy. Pregnancy constitutes a period of significant life change, requiring major psychological adjustments to the anxiety, tension, and stress often associated with it (Dragonas \& Chistodoulou, 1998; Elsenbruch et al., 2007). Moreover, the period of a woman's pregnancy is comprised of a constant tension between feelings of joy and excitement about the baby and future parenthood, as well as emotions of vulnerability and fear resulting from psychological and physiological changes of the body, coupled with uncertainties, fears, and concerns related to the pregnancy and its outcome. As Sjöström, Langius- 
Eklöf and Hjertberg (2004) pointed out, 'pregnancy is both biologically and psychologically a fruitful as well as vulnerable period' (p. 1112).

One of the most common fears and uncertainties associated with pregnancy is a concern regarding the well-being of the baby. Pregnant women are often worried that the baby might be born disabled or ill (Hanna-Leena \& Lauri, 1999), and fear that the baby might die and not survive the pregnancy (Tipping, 1981). Another common pregnancy-related fear, according to Jones (1990), is related to pregnant women's concern that they might do something that will harm the unborn fetus during the pregnancy, such as maintaining a diet that could harm the fetus while it develops in the womb, or taking certain medications that could cause birth defects.

Due to the prevalence of pregnancy-related fears, concerns, and uncertainties, pregnancy can be perceived as a condition that signals the need to acquire more knowledge and information (Aaronson, Mural \& Pfoutz 1988). Singh, Newburn, Smith and Wiggins (2002) surveyed firsttime mothers about their informational seeking during pregnancy. The women in their study were a representative sample of the childbearing population of England in terms of ethnicity, age and location. The results suggested that one of the reasons for informational needs during pregnancy is to acquire the ability to cope with the unknown. More specifically, $70 \%$ of the respondents said that they wanted 'a great deal' of information because they wanted 'to know as much as possible' (p. 55).

\section{Online Information Seeking During Pregnancy}

Previous studies (Gao et al, 2012; Lagan et al., 2010) examined the topics pregnant women seek online. The first study was conducted among 335 Chinese women (Gao et al, 2012).

The results of this study suggested that the most sought-after topics on the internet reported by pregnant women were fetal development (57\%), nutrition during pregnancy $(56 \%)$ and pregnancy complications (26\%). The second study (Lagan et al., 2010) was conducted among 613 women from 24 countries; most of them reside in the United Kingdom. The findings of this study showed that the most common Internet topics accessed by pregnant women were Antenatal complications (82.2\%), Intranatal issues $(37.2 \%)$ General pregnancy ailments and symptoms (33.6\%), Health promotion/ lifestyle issues $(20.9 \%)$, Fetal development $(18.4 \%)$, Medications in pregnancy (15.7\%), Pregnancy products (15.7\%), Antenatal investigations and screening (14\%), and Antenatal schedule (9.5\%).

\section{Prenatal Testing in Israel}

Since prenatal tests are immensely popular and widespread in Israel (Lavi, 2010; Mishori-Dery, Carmi \& Shoham-Vardi, 2007), it has become an integral part of an Israeli pregnancy experience. Prenatal diagnosis during pregnancy includes examining the fetus in the early stages of development inside the womb through the use of amniocentesis, ultrasound, and viral or blood analysis (Terrell, 2007). Gofin, Adler and Palti's (2004) survey of 
1,100 Israeli pregnant women who gave birth in March 2000 showed that nearly all of the women had an ultrasound scan during pregnancy. $98 \%$ of Jewish women and $95 \%$ of Arab women had an ultrasound scan, and $30 \%$ in both population groups reported having seven or more ultrasounds during pregnancy. The researchers concluded that ultrasound scans during pregnancy are nearly universally performed among Israeli pregnant women.

Mishori-Dery, Carmi, and ShohamVardi (2007) pointed out that several prenatal tests are routinely offered to pregnant women and costs are covered either by Israel's National Health Insurance program or by health management organizations. These routine tests include second and third trimester ultrasound screening scans, second trimester maternal serum screening (the so-called 'triple test'), carrier genetic testing for Tay-Sachs disease, and amniocentesis for women whose risk of having a child with neural tube defect, chromosomal abnormality or a molecularly defined genetic disease is above 1:380 (Mishori-Dery et al., 2007 , p. 243). The authors presented results of a national survey conducted in 2007 in Israel that suggested,

The rates of maternal serum screening, Tay-Sachs disease, and amniocentesis (at age 35 and older) among Jewish women were around $60 \%, 63 \%$, and $50 \%$, respectively. The uptake of ultrasound scans was very high and reached more than $95 \%$ of pregnant women. (p. 243).

\section{The Uses and Gratification Perspective as a Theoretical Framework}

The Uses and Gratifications Perspective (U\&G) serves as a theoretical framework for my research concerning informational needs for internet use during pregnancy. Uses and Gratifications research is a subtradition of media effects research (McQuail, 1994). Contrary to the dominant media effects tradition's focus on media messages and direct effects, U\&G research is primarily concerned with the individual's point of view regarding media use. Rather than looking for linear causal patterns, $U \& G$ research aims to explore the motives individuals have for media use and the gratifications they obtain from this use (Katz, Blumer, \& Gurrevitch, 1974; Rubin, 1994)

The U\&G perspective attempts to understand how individuals utilize media and their reasons for media consumption. The U\&G perspective suggests that individuals turn to specific media channels to fulfill specific cognitive or affective needs (Katz, Blumer \& Gurrevitch, 1974). The U\&G perspective, then, seeks to explain why individuals use media and to better understand motivations and needs when individuals select among media channels and content (Katz et al., 1974).

When the internet was first introduced to the general public, in the 1990s, scholars stated that the $U \& G$ perspective is applicable for internet research because of the mutability and interactive nature of the web (December, 1996; Newhagen \& Rafaeli, 1996). The call for using the $U \& G$ perspective in internet research was repeated a decade later. Stafford et al. (2004) noted that the U\&G perspective fits the exploration of the internet well because of the userdirected nature of the internet. Internet users exercise significant control over their exposure to different content and choose online activities; internet users 
are not passively consuming messages and online activities given to them.

Given that U\&G is highly applicable in the context of internet use and consumption, I believe that this theoretical framework will allow me to identify online information practices of pregnant women based on women's reports.

Thus, my research question for this study is:

RQ1: What kinds of health information do pregnant women seek online?

The aim of this research question was to better understand health information seeking practices of pregnant women, and thus shed more light on issues related to pregnancy Israeli women sought when utilizing the internet during pregnancy.

\section{Methodological Approach}

In this study I have utilized a qualitative research as the main methodological approach. I chose a qualitative approach because I wanted to gain a deeper understanding of pregnant women's online information seeking regarding their pregnancy and understand these experiences in a detailed manner (Creswell, 2003; Denzin \& Lincoln, 2005). In contrast to quantitative research, which aims to isolate causes and effects, operationalize theoretical relations, quantify phenomena, and allow generalization of findings, qualitative research does not aspire to fully quantify phenomena and completely generalize research findings to the general population (Flick, 2000). Rather, qualitative research aspires to understand human experiences and make sense of those experiences. As Rubin and Rubin (1995) stated 'Qualitative research is not about mere counting or providing numeric summaries. Instead, the objective is to discover variation, portray shades of meaning, and examine complexity' (p.202). Therefore, I believe that a qualitative approach would be more beneficial than a quantitative approach and more suitable for the question I wanted to explore.

\section{Interviews}

To collect data for this study, I conducted semi-structured, in-depth interviews with 50 pregnant women who had utilized the internet during their pregnancy. By using semistructured interviews, I could keep the interview flexible enough to enable interviewees to "shape the content of the interview' while also focusing on specific research questions (Bogdan \& Biklen, 1998, p. 4). This interview format allows for topics that interviewees find important to their experience that I might not have expected to emerge, while still accommodating topics related to my research question. The interview was designed as an in-depth format opens with a broad question and then probes the interviewees to explain and elaborate on their own experiences and views. The broad open-ended question was: 'What kind of information do you seek online in terms of your pregnancy?'.

The aim of this question was to allow interviewees to share experiences regarding their pregnancy- 
related online information seeking. For example, if an interviewee said that she was seeking online information regarding prenatal tests, she was asked to elaborate, provide examples, and describe the relevant context in a detailed manner. This was done systematically throughout the interviews, since it is the recommended approach in qualitative research in order to achieve a rich and detailed description (Denzin \& Lincoln, 2005; Rubin \& Rubin, 1995; Warren, 2002). This question was developed based on relevant literature (Lagan, Sinclair \& Kernohan, 2006; Romano, 2007) and four pilot interviews. The aim of pilot interviews is to test the interview question for clarity and effectiveness and allow the researcher to make necessary revisions prior to the implementation of the interview (Turner, 2010).

\section{Recruitment of Participants}

This study was a part of a larger study focusing on internet use by Israeli pregnant women during pregnancy. After obtaining an IRB approval for this research project, I interviewed 50 Israeli pregnant women in Israel. Interviews took place over a period of three and a half months. Participants were recruited in two ways. The first method of participants' recruitment was with the cooperation and assistance of a women's Health Care Medical Center in Northern Israel. This center is a large clinic in Northern Israel providing prenatal health care to hundreds of pregnant women in the region. Twenty interviewees out of the final pool of 50 were recruited through the health care center. The second way of recruiting participants was through 'snowballing' among friends and acquaintances in Israel. Using this method, I recruited 30 interviewees out of the final pool of 50. The snowball interviews were conducted in a variety of locations, such as the women's homes, coffee shops, restaurants and workplaces. Interviews typically lasted between one to two hours and were recorded and transcribed.

\section{Data Analysis}

After the interviews were recorded and transcribed, the data were analyzed using thematic analysis. A theme is 'a pattern found in the qualitative information that at minimum describes and organizes the possible observation and at maximum interprets aspects of the phenomenon' (Boyatzis, 1998, p. 4). Thematic analysis is a process that allows the qualitative researcher to organize and effectively communicate the findings and interpretations of meaning within the data.

First, I transcribed the interviews using a digital voice editor and typed the content of the interviews into a Word document. Second, I printed all the transcripts and read through them several times for major themes.

After several readings, I began coding the data for major themes and interpreted the data to answer my research question. Third, I translated the material from Hebrew to English.

The decision to conduct the coding of the interview data in Hebrew stemmed from my wish to respect the voices of my interviewees. Conducting the thematic analysis in Hebrew allowed me to better represent the language choices of my interviewees and enabled me to provide a more 
authentic account of participants' experiences.

\section{The Demographic Characteristics of Interviewees}

Fifty Israeli pregnant women participated in this study. Table 1 presents the socio- demographic characteristics of participants and also provides internet use characteristics.

\section{Pregnancy-related Online Information Seeking Practices}

The most popular method for searching pregnancy-related online information was by typing keywords as search queries in the Google search engine. Thirty six interviewees $(72 \%)$ stated that they used Google to find information about specific issues or as a means to get to pregnancy-related internet websites. The vast majority of interviewees $(n=44,88 \%)$ said that they usually perform Google searches in Hebrew; only six women (12\%) said that they perform Google searches in English in addition to their Hebrew searches. Six interviewees (12\%) stated that they do not have a preference for a specific pregnancy-related website. The rest of the interviewees said that they are loyal to one or two websites that they use for pregnancy-related purposes. All the preferred internet websites women mentioned visiting are Israeli websites, written in Hebrew, and targeted especially toward pregnant women.

\section{Findings}

The interview data revealed that the most prominent type of information sought by Israeli pregnant women online was focused on prenatal tests. This theme included three subcategories: keeping track of prenatal test schedule; interpretation of prenatal test results; and, information on amniocentesis.

\section{Keeping Track of Prenatal Test Schedule}

Due to the relatively high number of prenatal tests performed during pregnancy in Israel and the fact that some prenatal tests need to be conducted at a certain time during the pregnancy, Israeli women utilize the internet to keep track of their prenatal testing schedule. As the following interviewees explained,

I keep track of my prenatal testing schedule using a website that sends you reminders. It's really helpful, because sometimes I do not remember when I have to do a certain test, so I have all this information organized and I find it useful. (Interviewee \# 45)

I use the internet to check when I need to do the prenatal tests. I check the prenatal testing schedule according to the weeks of pregnancy to make sure that I am not missing any test. (Interviewee \# 20)

I use an internet website where you can type in the last day of your period, and then it gives you a list of all the tests you need to do. I think it is important to know which tests you need to do every week, which prenatal tests are elective, which are more important than others. (Interviewee \# 37) 
I utilize the internet to calculate when I need to schedule an appointment for each test. There is a nice calculator on one of the websites that you plug in the date your last period, and it gives you a table with dates of the prenatal tests you should do every week. (Interviewee \# 10)

I utilize a prenatal tests calculator on the internet which tells me what tests I need to do every week. (Interviewee \# 49)

I am using an internet calculator to keep track of the dates for my prenatal tests. You put the date of your last period, and it tells you every week what tests you need to do according to the week of pregnancy. (Interviewee \# 28)

These quotes illustrate the importance women ascribe to following the schedule for their prenatal tests and making sure that they do not miss any time window for these tests. The internet is perceived to be a helpful tool because there are websites that contain a prenatal tests calculator function. Using this function, women can plug in the date of their last period and get a time table which directs them to the kinds of prenatal tests they should do every week. Additionally there are websites which provide women reminder e-mails about their prenatal testing schedule. Only a few interviewees mentioned a list of prenatal tests given to them by their gynecologists in hard copy at the beginning of the pregnancy as a means of keeping track of this schedule. The online prenatal tests calculators seemed to be popular among interviewees who felt that it was a beneficial way of keeping track of their long list of prenatal tests.

\section{Using the Internet to Interpret Test Results}

The second type of information related to prenatal tests frequently mentioned by women was the need for information to interpret prenatal test results. Interviewees said that, when they get the results of their prenatal tests, usually blood tests, they turn to the internet to explore what the results mean.

I usually go to websites that allow you to interpret blood test results. Every blood test result that I get, I immediately go online to see what it means.

(Interviewee \# 47)

Whenever I get my test results, the first thing I do is go to the internet and type the results in Google, or look in Wikipedia to see what it means. Often when you get your tests results, it does not say what it means. You have three English letters, and that's it. I need to understand. (Interviewee \# 7)

When I get the results of my blood test, I want to know what it means. So I go to Google and search the name of the test to read about it. (Interviewee \# 8)

I search the internet to read about prenatal test results. When I get my test results, I want to know what it means before I go to the doctor. (Interviewee \# 32) 
These women highlight a need to understand and interpret the meaning of their test results. They even use the internet before going to their physician to get an explanation and interpretation of the results. The internet, as a tool for obtaining information about tests results, does not fully substitute for the physician in providing an explanation of the results. Rather, it serves as a quicker means of getting this information to satisfy this need. Because the internet is available, and because the practice of searching for information about test results is perceived as relatively easy, interviewees choose not to wait and experience uncertainty about their test results before they see a physician. Instead, the internet enables them to be more self-sufficient and obtain this information more quickly. According to the interviews, the most common reason for searching the internet to interpret test results was the need to know whether the results were within the normal range. One interviewee, a 27 year old, in her second pregnancy explained,

When I get my test results, I look for information on the internet to see if my results are in the norm. (Interviewee \# 11)

This tendency of going online to obtain information about prenatal test results was echoed by additional interviewees.

I usually go online to explore the results of my blood tests. I need to know they are falling in the norm and if it's okay. (Interviewee \# 13)

I go online to see what my test results mean, especially blood tests, such as sugar level and iron level. When you are pregnant, sometimes your blood test results are outside the norm, and it can be reasonable because of the pregnancy, but to be sure, I go online to read about it and see if it is okay. (Interviewee \# 19)

When I get the results of my blood tests from the lab, I check on the internet to see what it means if there is a test result that is not in the norm. (Interviewee \# 44)

I was searching the internet after each and every blood test I had to understand what the results mean. It's helping me to decrease my level of anxiety, because I can find out if my tests results are normal. (Interviewee \# 23)

A common goal reported by pregnant women in searching for information about blood test results is to make sure that results are in the normal range. Interviewees feel that a 'normal' result provides reassurance that their pregnancy is progressing as it should and that there are no concerns with their current medical condition. This reassurance, as interviewee \# 23 explained, is helpful in easing fears and anxiety about possible medical complications.

\section{Using the Internet to Seek Information about Amniocentesis}

The third type of information Israeli pregnant women seek online regarding prenatal tests concerns a specific prenatal test called 'amniocentesis'. Amniocentesis is a prenatal test to detect a number of genetic and chromosomal abnormalities in the 
fetus. It is a diagnostic procedure in which fluid is drawn from the amniotic sac surrounding the fetus (Rapp, 1994). According to Robertson (2006), this test can detect chromosomal disorders such as Down Syndrome, structural defects such as spina bifida (open spine, where the vertebrae fail to close) and anencephaly (a condition in which the brain is incomplete or missing), and several metabolic disorders.

Amniocentesis is typically conducted in Israel between week 16 and 20 of the pregnancy for women who have one or more medical indications based on other prenatal tests, such as the triple screen test and ultrasound screening scans, or if the woman is older than 35 . The test itself is performed by inserting a hollow needle through the abdominal wall into the uterus and withdrawing a small amount of fluid from the sac surrounding the fetus (Robertson, 2006). The internet is used by Israeli pregnant women to obtain more information about this test.

I was searching the web for information on amniocentesis when I tried to understand the risks of this test and what it is. I just Googled the term amniocentesis and read what I found. The internet assisted me in getting a detailed explanation about this test. (Interviewee \# 40)

I read a lot on the internet about amniocentesis. I mainly searched this term using Google. I even entered an online forum where people discussed this test to see what they say. A month before the amniocentesis test I had some contractions and I was really stressed about it because it is a very invasive procedure and it can risk the pregnancy. (Interviewee \# 44)

I was in a lot of stress before my amniocentesis. Because of my age, they recommended that I do the test and I feared this test, so I spent days on the internet reading everything I could about amniocentesis. I wanted to get confirmation about the decision to do the test and read research about it to know the possible risks. I think that reading about it on the internet made me feel more relaxed. (Interviewee \# 25)

The aforementioned quotes indicate that the main reason Israeli pregnant women report a need to acquire more information on amniocentesis is to better understand the risks involved in this procedure. Because amniocentesis is invasive, it poses risks. (Robertson, 2006). Pregnant women who choose to perform this test know that, in addition to its benefits of detecting fetus abnormalities, the procedure can risk the pregnancy. Women reported seeking information about the possible risks of this procedure to learn more about the implications of this test and to confirm their decision to do the test. While the most common reason given for obtaining information on the internet regarding amniocentesis was associated with the risks, one interviewee, a 29 year old in her second pregnancy, explained that her motivation to get information was the fear of the procedure itself.

I had to decide whether to perform an amniocentesis. So I read about it on the internet, especially in forums of pregnant women. 
And it made me realize that this test is not so awful. I feared this procedure, and I corresponded with other pregnant women who had this procedure. I mainly asked them questions about this test. (Interviewee \# 30)

Online pregnancy forums provide Israeli pregnant women with the opportunity to correspond with other pregnant women who have had this test and to read other women's experiences of this procedure. This type of information that goes beyond mere clinical facts, is based on personal experiences, and usually encapsulates descriptions of physical and emotional sensations and thus, can reduce the amount of uncertainty surrounding this procedure and consequently ease fears and concerns.

\section{Discussion}

The findings of this study revealed that the most prominent type of information sought by Israeli pregnant women who use the internet was related to prenatal tests. Israeli pregnant women might be interested in prenatal testing information on the internet because of the salience of this issue within the Israeli health care system (Lavi, 2010; Remennick, 2006; Weiss, 2002). Prenatal tests evolved to become an inseparable and dominant element of the experience of pregnancy in Israel. The prominence of prenatal tests in an Israeli pregnancy is manifested by the number of prenatal tests, the amount of time Israeli pregnant women spend in undergoing these tests, and the time and energy Israeli women devote to making sense of this process. As Dervin (1983,
1992) explained, 'making sense' of the situation is a human need which drives information seeking. When Israeli women are pregnant, they find themselves under a highly medicalized scrutiny in the form of many prenatal tests. Therefore, they feel a need to acquire information about these tests to better understand the meaning and the implications of the procedures that they are going through.

The relatively high frequency of prenatal testing during a pregnancy in Israel (Mishori-Dery, Carmi, \& Shoham-Vardi,2007), combined with the fact that many of these tests need to be performed during a specific period, creates a need for pregnant women to maintain a relatively loaded test schedule. Thus, many women use the internet as a resource to keep track of their prenatal testing schedule using various online applications designed for this purpose.

The second type of information regarding parental tests interviewees sought was related to the interpretations of prenatal test results. Most Israeli HMO's internet websites include the option of obtaining test results online without the need to call or come to the clinic. This option creates a situation in which pregnant women can obtain their test results online before seeing their health care provider. Interview data indicated that many pregnant women use the internet to self-interpret their test results before their doctor's visit. Interviewees explained that making sense of their test using online resources was a way to get peace of mind and to make sure that everything was normal.

Women's use of online information to interpret test results can help address common fears often associated 
with pregnancy (Hanna-Leena \& Lauri, 1999; Heper, Cohen, Beiteman \& Eaton, 1968; Tipping, 1981). The eagerness of women to self-interpret prenatal test results fulfills cognitive needs to know but also addresses emotional needs. Prenatal test results can alleviate concerns and fears about the well being of the pregnancy. Israeli pregnant women's use of information resonates with existing literature (Shiloh et al., 1999; Song et al., 2012) suggesting that acquiring information is seen as desirable because of both its instrumental value and its emotional value as a guard against stress.

Pregnant women's selfinterpretation of their prenatal test results online may also reflect a trend toward a more proactive and involved patient (Neelapala et al., 2008; Wald, Dube \& Anthony, 2007). The internet, in this case, is used not just to satisfy curiosity, but as a diagnostic aid. The fact that women find it important to engage in self-interpretation with respect to their test results demonstrates a higher level of involvement within the process of health care.

Self interpretation of test results can be difficult for lay individuals. Interview data suggested that women generally find this practice helpful in decreasing anxiety and stress. This finding might not be surprising in cases of normal test results. However, the consequences of online-self interpretation of test results that might indicate a problem with the pregnancy might have different implications. Clearly, one of the most challenging aspects of online information seeking is the constant need to evaluate online information. More specifically, this need requires a distinction between reliable, good quality information and unreliable, misleading information on the internet (Morahan-Martin, 2004). Evaluating online information can be even more complicated when lay internet users have to evaluate medical information in the absence of professional training and knowledge. This challenge, however, does not seem to deter Israeli pregnant women from conducting Google searches to satisfy pregnancyrelated informational needs or to locate medical information. Therefore, it is important for pregnant women to be critical consumers of the information they obtain online. The notion of being a critical consumer should begin with women's choice of online sources. Although Google searches might be helpful in locating specific types of information, they might not always direct users to reliable and good quality websites. Surprisingly, the issue of reliability and mistrust of online information related to prenatal tests did not emerge from the interviews in this study; despite other findings (Usui et al., 2011) indicate that pregnant women are suspicious about medical information on the Internet, especially in cases of abnormal pregnancy.

The third type of prenatal test information Israeli pregnant women seek on the internet was related to amniocentesis. The reason for the prevalence of amniocentesis information seeking can be explained in light of the characteristics of this test. First, amniocentesis is an invasive procedure and, as such, poses risks such as infection, injury to the fetus, or miscarriage (Robertson, 2006). The risks associated with amniocentesis create informational needs. Second, amniocentesis is not mandatory, 
but elective. Recommendations for amniocentesis are typically based on prenatal screenings or a physician recommendation. Many pregnant women and their partners have to decide whether to have amniocentesis. The decision might not be easy because of the risks to the pregnancy. As a result, some Israeli pregnant women turn to the internet to acquire information that will assist them in making an informed decision.

Overall, this study confirms that individuals actively use media to satisfy various human needs (Katz, Blumer, \& Gurrevitch, 1974; Katz, Gurevitch, \& Haas, 1973; Rubin, 1983). The findings also echo other U\&G studies (Charney \& Greenberg, 2002; Diddi \& Larose, 2006; Johnson \& Kaye, 2003) that indicated the prominence of informational needs as a reason for using the internet. The study's findings indicated that pregnancy-related internet use is a purposeful activity that is generally perceived as valuable during pregnancy.

Another contribution of this study to $U \& G$ research lies in its use of qualitative methodology and its focus on the context of health. Because most of the U\&G research is based on a quantitative approach, Ruggiero (2000) asserted that 'communication researchers should be encouraged to employ U\&G more frequently in conjunction with qualitative methodologies' (p. 24). This study demonstrated that a qualitative inquiry can be a beneficial way of exploring in-depth media uses and gratifications based on users' personal accounts and experiences. In addition to the methodological contribution of this study, it is important to note that few
U\&G studies have explored media use related to health issues (Chung \& Sujin, 2008; Nwagwu, 2007). This study contributes to literature of $U \& G$ within the context of health and stresses the importance of future inquiries within this context.

\section{Limitations and Directions for Future Research}

Like any study, the present research has limitations. The first limitation concerns the diversity of the sample. The vast majority of interviewees were Ashkenazi Jewish women in their 30s. This type of inquiry could benefit from a pool of interviewees representing a more diverse population in terms of ethnicity, religion and age. Second, the vast majority of interviewees had been using the internet for about a decade, and thus were experienced internet users. It would be interesting to explore pregnancy-related internet use among pregnant women who have not been using the internet for many years and have less experience in using the internet. Third, this study was conducted in Israel. Future studies could be conducted in other countries and cultural contexts to see to what extent non-Israeli's internet use resembles or differs from Israelis.

It is important to remember that the sample of interviewees in this study intentionally included only pregnant women who were carrying one fetus and were going through a healthy pregnancy that was not considered high-risk. Therefore, the findings cannot speak as to the experiences and pregnancy-related internet use of women with high risk pregnancies or 
women carrying more than one fetus. It would be interesting to conduct future research exploring internet use and pregnancy related information seeking of women with high risk pregnancies or with multiple fetuses to see whether these women have different informational needs and online practices.

On a more critical note, it can be argued that the constant need of Israeli pregnant women to consult the internet regarding prenatal tests is also a response to social and cultural needs created by the medicalization of pregnancy and commercialization of prenatal care. As Remennick (2006) writes, prenatal testing 'casts a shadow on the whole experience of pregnancy, causing many women anxiety and stress' (p. 22). Thus, the internet as a source of pregnancy-related information in general and prenatal testing in particular seems to function not just as a means to fulfill personal informational needs, but also to represent a broader social phenomenon of a highly medicalized pregnancy that seem to intensify uncertainty and stress, and therefore, to increase women's need to constantly rely on the internet during pregnancy.

\section{References}

Aaronson, L. S., Mural, C. M., \& Pfoutz, S. K. (1988) Seeking information: Where do pregnant women go? Health Education Quarterly, 15(3): 335-345.

Babrow, A. S. (2001) Communication and uncertainty management. Journal of Communication, 51(3): 477-497.

Bogdan, R.C., \& Biklen, S.K. (1998) Qualitative research for education: An introduction to theory and methods. Boston: Allyn and Bacon.

Boyatzis, R. E. (1998) Transforming qualitative information: Thematic analysis and code. Thousand Oaks, CA: Sage.

Charney, T., \& Greenberg, B. S. (2002) Uses and gratifications of the internet. In C. A. Lin \& D. J. Atkin (Eds.), Communication technology and society (pp. 379-407). Cresskill, NJ: Hampton Press.

Chung, D. S., \& Sujin, K. (2008). Blogging activity among cancer patients and their companions: Uses, gratifications, and predictors of outcomes. Journal of the American Society for Information Science and Technology, 59(2): 297-306 Creswell, J. W. (2003) Research design: Qualitative, quantitative, and mixed methods approaches. Thousand Oaks, CA: Sage.

Crum, J. A. (2000) The Whole nine months and then some: Pregnancy, childbirth, and early parenting resources on the internet. In M. S. Wood \& J. M. Coggan (eds.), Women's health on the internet (pp. 99-111). Binghamton, NY: Haworth Press.

December, J. (1996) Units of analysis for internet communication. Journal of Communication, 46(1): 14-38.

Denzin, N. K., \& Lincoln, Y. S. (2005) The discipline and practice of qualitative research. In N. K. Denzin \& Y. S. Lincoln (eds.), The Sage handbook of qualitative research third edition (pp. 1-32). Thousand Oaks, CA: Sage. 
de Jong, A., Dondorp, W.J., Die-Smulders, D.E, Frints, S.E.M.,de Wert, G.M. (2010). Non-invasive prenatal testing: Ethical issues explored. European Journal of Human Genetics, 18: 272-277.

Dervin, B. (1983) Information as a user construct: The relevance of perceived information needs to synthesis and interpretation. In S.A. Ward \& L.J. Reed (eds.), Knowledge structure and use: Implications for synthesis and interpretation (pp. 153-184). Philadelphia: Temple University Press.

Dervin, B. (1992) From the mind's eye of the user: The sense-making qualitativequantitative methodology. In J. Glazier \& R. Powell (eds.), Qualitative research in information management (pp.61-84). Englewood, CO: Libraries Unlimited.

Diddi, A., \& LaRose, R. (2006) Getting hooked on news: Uses and gratifications and the formation of news habits among college students in an internet environment. Journal of Broadcasting \& Electronic Media, 50(2): 193-210 Dragonas, T., \& Christodoulou, G. N. (1998). Prenatal Care. Clinical Psychology Review, 18(2): 127-142.

Elsenbruch, S., Benson, S., Rücke, M., \& Dudenhausen, J. (2007) Social support during pregnancy: Effects on maternal depressive symptoms, smoking and pregnancy outcome. Human Reproduction, 22(3): 869-877.

Flick, U. (2002) An introduction to qualitative research (2nd ed.). London: Sage. Fox, S. (2011) Accessing Health Topics on the Internet., Pew Internet \& American Life Project, Washington, DC. Web site: http://pewresearch.org/pubs/1875/internethealth-topics-accessing-updated-data (consulted, 30, August, 2012).

Gao, L.L., Larsson, M., \& Luo, S.Y. (2012) Internet use by Chinese women seeking pregancy-related information. Midwifery. http://dx.doi.org/10.1016/j. midw.2012.07.003 (consulted, 8, March, 2013).

Gofin, R., Adler, B., \& Palti, H. (2004) Screening tests in prenatal care: A national study in Israel. Israeli Medical Association Journal, 6: 535-539.

Hanna-Leena, M., \& Lauri, S. (1999) Fears associated with pregnancy and childbirth: Experiences of women who have recently given birth. Midwifery, 15(3): 177-182.

Heper, M.M., Cohen, R.L., Beiteman, E.T., \& Eaton, L. (1968) Life-events and acceptance of pregnancy. Journal of Psychosomatic Research, 12: 183-188. Johnson, T. J., \& Kaye, B. K. (2003) Around the World Wide Web in 80 days. Social Science Computer Review, 21(3): 304-325.

Jones, K. (1990) Expectant fears. Nursing Times, 86: 36-38.

Katz, E., Blumer, J.G., \& Gurevitch, M. (1974) Uses of mass communication by the individual. In W.P. Davidson (Ed.), Mass communication research: Major issues and future directions (pp.11-35). New York: Praeger.

Katz, E., Gurevitch, M., \& Hass, H. (1973) On the use of mass media for important things. American Sociological Review, 38: 164-181.

Lagan, B., Sinclair, M., \& Kernohan, W. G. (2006) Pregnant women's use of the internet: A review of published and unpublished evidence. Evidence Based Midwifery, 4(1): 17-23.

Lagan, B., Sinclair, M., \& Kernohan, W. G. (2010) Internet use in pregnancy informs women's decision making: A web-based survey. Birth, 37: 106-115. Lavi, S. (2010) The paradox of Jewish bioethics in Israel: The case of reproductive 
technologies. In A. Voigt (Ed.), Religion in bioethischen Diskursen: Interdisziplinäre, internationale und interreligiöse Perspektiven, 23: 81-102. Lemire, M., Pare, G., Sicotte, C., \& Harvey, C. (2008) Determinants of internet use as a preferred source of information on personal health. International Journal of Medical Informatics, 77(11): 723-734.

Lorence, P. L., Park, H., \& Fox, S. (2006) Assessing health consumerism on the web: A demographic profile of information-seeking behaviors. Journal of Medical Systems, 30(4): 251-258.

Mano, Mesch,\& Tsamir (2011) Social Inequalities in Access and Use of Information and Health Electronic Services in Israel. Maccabi Health Services Research Fund: Tel Aviv.

McQuail, D. (1994) The rise of media of mass communication. In D. McQuail (Ed.), Mass communication theory: An introduction (pp.1-29). London: Sage. Mishori-Dery, A., Carmi, R., \& Shoham-Vardi, I. (2007) Different perceptions and attitudes regarding prenatal testing among service providers and consumers in Israel. Community Genetics, 10(4): 242-251.

Morahan-Martin, J. M. (2004) How internet users find, evaluate, and use online health Information: A cross-cultural review. CyberPsychology \& Behavior, 7(5): 497-510.

Neelapala, P., Duvvi, S. K., Kumar, G., \& Kumar, B. N. (2008) Do gynecology outpatients use the internet to seek health information? A questionnaire survey. Journal of Evaluation in Clinical Practice, 14(2): 300-3004.

Newhagen, J.E., \& Rafaeli, S. (1996) Why communication researchers should study the internet: A dialogue. Journal of Communication, 46: 4-13.

Nwagwu, W. E. (2007). The Internet as a source of reproductive health information among adolescent girls in an urban city in Nigeria. BMC Public Health, 7(354). unpaginted, Retrieved September 1, 2012 from: http://www.biomedcentral.com/ content/pdf/1471-2458-7-354.pdf

Rapp, R. (1994) The power of 'positive' diagnosis: Medical and maternal discourses on amniocentesis. In D. Bassin, M. Honey, \& M. M. Kaplan (Eds.), Representation of motherhood (pp. 204-219). New Haven, CT: Yale University Press.

Remennick, L. (2006) The quest for the perfect baby: Why do Israeli women seek prenatal genetic testing? Sociology of Health and Illness, 28(1): 21-53.

Robertson, A. (2006) Medlineplus medical encyclopedia. http://www.nlm.nih.gov/ medlineplus/ency/article/003921.htm (consulted, 18, Aug, 2012).

Rubin, H.J., \& Rubin, I.S. (1995). Qualitative interviewing: The art of hearing. Thousand Oaks, CA: Sage.

Romano, A. (2007) A changing landscape: Implications of pregnant women's internet use for childbirth educators. Journal of Prenatal Education, 16(4): 1824.

Rubin, A.M. (1983) Television uses and gratifications: The interactions of viewing patterns and motivations. Journal of Broadcasting, 27: 37-51.

Rubin, A.M. (1994) Audience activity and media use. Communication Monographs, 60, 98-105.

Ruggiero, T. E. (2000) Uses and gratifications theory in the 21st century. Mass Communication \& Society, 3(1): 3-37. 
Shiloh, S., Ben-Sinai, R., \& Keinan, G. (1999) Effects of controllability, predictability, and information seeking style on interest in predictive genetic testing. Personality \& Social Psychology Bulletin, 25(10): 1187-1195.

Singh, D., Newburn, M., Smith, N., \& Wiggins, M. (2002) The information needs of first-time pregnant mothers. British Journal of Midwifery, 10(1): 54-58.

Sjöström, H., Langius-Eklöf , A., \& Hjertberg, R. (2004) Well-being and sense of coherence during pregnancy. Acta Obstetricia Et Gynecologica Scandinavica, 83(12): 1112-1118.

Song, F.W., West, J.E., Lundy, L., \& Smith-Dahmen ,N. (2012) Women, Pregnancy, and Health Information Online: The Making of Informed Patients and Ideal Mothers. Gender \& Society, 26: 773-798.

Stafford, T. F., Stafford, M. R., \& Schkade, L. L. (2004) Determining uses and gratifications for the internet. Decision Sciences, 35(2): 259-288.

Stern, M.J., Cotten, S. R., \& Drentea, P. (2012) The separate spheres of online health gender, parenting, and online health information searching in the information age. Journal of Family Issues, 33(10): 1324-1350

Talosig-Garcia, M., \& Davis, S. (2005) Information-seeking behavior of minority breast cancer patients: An exploratory study. Journal of Health Communication, 10(1): 53-64.

Tang, E., \& Lee, W. (2006) Singapore internet users' health information search: Motivation, perception of information sources, and self efficacy. In M. Murero \& R. E. Rice (Eds.), The internet and health Care: Theory, research, and practice (pp. 107-126). Mahwah, NJ: Lawrence Erlbaum.

Terrell, P. E. (2007) Counseling pregnancy, politics, and biomedicine: Empowering discernment. Binghamton, NY: Haworth Pastoral Press.

Tipping, V. G. (1981) The vulnerability of a primipara during the antepartal period. Maternal Baby Nursing Journal, 10: 61-77.

Turner, D. W. (2010) Qualitative interview design: A practical guide for novice investigators. The Qualitative Report, 15(3): 754-760.

Usui, N., Kamiyama, M., Tani, G., Kanagawa, T., \& Fukuzawa, M. (2011) Use of the medical information on the internet by pregnant patients with a prenatal diagnosis of neonatal disease requiring surgery. Pediatric surgery international, 27(12): 1289-1293.

Wald, H. S., Dube, C. E., \& Anthony, D. C. (2007) Untangling the web: The impact of internet use on health care and the physician-patient relationship. Patient Education and Counseling, 68(3): 218-224.

Warren, C. A. (2002) Qualitative interviewing. In J. F. Gubrium \& J. A. Holstein (Eds.), Handbook of interview research: Context and method (pp. 83-101). Thousand Oaks, CA: Sage.

Weiss, M. (2002) The chosen body: The politics of the body in Israeli society. Stanford, CA: Stanford University Press.

Young, I. M. (1995) Pregnant embodiment: Subjectivity and alienation. In N. Tuana \& R. Tong (eds.), Feminism and philosophy: Essential readings in theory, reinterpretation, and application (pp. 407-430). Boulder, CO: Westview Press. 


\section{Annex}

Table 1: Socio-demographic characteristics of participants

\begin{tabular}{|c|c|c|}
\hline Characteristics & $\mathrm{n}(\mathrm{Total}=50)$ & $\%$ \\
\hline Age (mean, range) & $31,26-37$ & \\
\hline \multicolumn{3}{|l|}{ Marital status } \\
\hline Married & 47 & $94 \%$ \\
\hline Single & 2 & $4 \%$ \\
\hline Divorced & 1 & $2 \%$ \\
\hline \multicolumn{3}{|l|}{ Pregnancy number } \\
\hline First pregnancy & 21 & $42 \%$ \\
\hline Second pregnancy & 18 & $36 \%$ \\
\hline Third pregnancy & 9 & $18 \%$ \\
\hline Fourth pregnancy & 2 & $4 \%$ \\
\hline \multicolumn{3}{|l|}{ Pregnancy trimester when interview was conducted } \\
\hline First Trimester & 6 & $12 \%$ \\
\hline Second Trimester & 15 & $30 \%$ \\
\hline Third Trimester & 29 & $58 \%$ \\
\hline \multicolumn{3}{|l|}{ Ethnic background } \\
\hline Israeli-born Ashkenazi (Jews of European origin) & 36 & $72 \%$ \\
\hline $\begin{array}{l}\text { Israeli-born Mizrahi (Jews of Spanish, North African, or } \\
\text { Asian origin) }\end{array}$ & 6 & $12 \%$ \\
\hline Mixed Ashkenazi and Mizrahi & 4 & $8 \%$ \\
\hline Arab & 2 & $4 \%$ \\
\hline Jewish Russian Immigrants & 2 & $4 \%$ \\
\hline Internet connection \& Access at home & 50 & $100 \%$ \\
\hline Internet connection \& Access at work & 47 & $94 \%$ \\
\hline \multicolumn{3}{|l|}{ Frequency of internet use for general purposes } \\
\hline Daily basis & 49 & $98 \%$ \\
\hline Once a week & 1 & $2 \%$ \\
\hline \multicolumn{3}{|l|}{ Frequency of internet use for pregnancy-related purposes } \\
\hline Daily basis & 20 & $40 \%$ \\
\hline 5 times a week & 2 & $4 \%$ \\
\hline Once a week & 8 & $16 \%$ \\
\hline Twice a week & 6 & $12 \%$ \\
\hline Three times a week & 3 & $6 \%$ \\
\hline Twice a month & 2 & $4 \%$ \\
\hline Once a month & 2 & $4 \%$ \\
\hline Only in case of a specific need & 7 & $14 \%$ \\
\hline
\end{tabular}


